\title{
Formula of compressibility and using it for air, noble gases, some hydrocarbons gases, some diatomic simple gases and some other fluids
}

\author{
Marwan Al-Raeei ${ }^{*}$ (D) and Moustafa Sayem El-Daher ${ }^{2,3}$
}

\begin{abstract}
Based on solutions of the Ornstein-Zernike equation (OZE) of Lennard-Jones potential for mean spherical approximation (MSA), we derive analytical formula for the compressibility assuming that the system is of low density, homogeneous, isotropic and composed of one component. Depending on this formula, we find the values of the bulk modulus and the compressibility of air at room temperature and the bulk modulus and the compressibility of Methane, Ethylene, Propylene and Propane at nine per ten of critical temperature of each hydrocarbon. Also, we find the speed of sound in the air at various temperatures, the speed of sound in each of Helium, Neon, Argon, Krypton, Xenon, Methane, Ethylene, Propylene, Propane, Hydrogen, Nitrogen, Fluorine, Chlorine, Oxygen, Nitrous oxide (laughing gas), Carbon dioxide, Nitric oxide, Carbon monoxide, Sulphur dioxide and dichlorodifluoromethane at room temperature. Besides, we find the speed of sound in Methane, Ethylene, Propylene and Propane at nine per ten of critical temperature of each hydrocarbons depending on the formula we find. We show that the simple formula we derive in this work is reliable and agrees with the results obtained from other studies and literatures. We believe it can be used for many systems which are in low densities and described by Lennard-Jones potential.

Keywords: Compressibility, Lenard-Jones potential, Bulk modulus, One component fluid, Bulk modulus, Static structure factor, Ornstein-zernike equation and radial distribution function, Speed of sound, Critical temperature, Simple fluid
\end{abstract}

\section{Background}

The compressibility is one of the most important properties in thermodynamic of materials, and we can get it from experimental methods or from some theoretical methods. In this work we find analytical formula of the compressibility from the Ornstein-Zernike equation which is one of the basic equations used to study the physical properties of fluids because this equation enables us to find the physical properties of materials by

\footnotetext{
*Correspondence: mhdm-ra@scs-net.org; mn41@live.com

${ }^{1}$ Faculty of Sciences, Damascus University, Damascus, Syrian Arab Republic

Full list of author information is available at the end of the article
}

theoretical ways. For one component system, the Ornstein-Zernike equation in the homogeneous formalism is given as follows [1-7]:

$$
h(r)=c(r)+\rho \int d \vec{r}^{\prime} c\left(\left|\vec{r}-\vec{r}^{\prime}\right|\right) h\left(r^{\prime}\right)
$$

where $c(r)$ is the direct correlation function, $h(r)$ is the total correlation function, $\rho$ is particle's density and $r$ is the position and the integral is over the volume of position of the particles. The Ornstein-Zernike equation is considered a very important equation in the statistical mechanics and materials sciences, especially, in the static formalism because by solving this equation we find the

(c) The Author(s) 2020. This article is licensed under a Creative Commons Attribution 4.0 International License, which permits use, sharing, adaptation, distribution and reproduction in any medium or format, as long as you give appropriate credit to the original author(s) and the source, provide a link to the Creative Commons licence, and indicate if changes were made. The images or other third party material in this article are included in the article's Creative Commons licence, unless indicated otherwise in a credit line to the material. If material is not included in the article's Creative Commons licence and your intended use is not permitted by statutory regulation or exceeds the permitted use, you will need to obtain permission directly from the copyright holder. To view a copy of this licence, visit http://creativeco mmons.org/licenses/by/4.0/. The Creative Commons Public Domain Dedication waiver (http://creativecommons.org/publicdomain/ zero/1.0/) applies to the data made available in this article, unless otherwise stated in a credit line to the data. 
radial distribution function (RDF) of a specific system which enables us to find a lot of properties of the material by applying the integration of a certain property on this function. We can find a solution for the OrnsteinZernike equation using a suitable interaction potential of the system, however, we need another equation between pair potential and the total correlation function or the direct correlation function which we get it from a number of possible approximations of the direct correlation function which are used in the theory of simple liquids or simple fluids such as Born Green Yvon approximation (BGYA), Hyper Netted Chain approximation (HNCA), Percus Yevick approximation (PYA) and mean spherical approximation (MSA). All of these approximations give closed relations between the direct correlation function and the interaction potential of the system either in a linear form or in a nonlinear form [8-25]. In this work, we use the mean spherical approximation to find the solutions of the Ornstein-Zernike equation where this approximation relates the direct correlation function and the interaction potential via a linear formula. The direct correlation function based on the mean spherical approximation is given as follows [2, 4-7]:

$$
c(r) \approx-U(r) /\left(k_{B} T\right) ; r>d
$$

where $k_{B}$ is Boltzmann constant, $T$ is absolute temperature and $d$ is the diameter of particles while $U(r)$ is the interaction potential between the particles of the system. The interaction potential which we used in this work is Lenard-Jones potential, which is very important as a fitting potential and a structure potential in a lot of studies such as soft materials and simple fluids [3, 8-24] and this potential is given by the following formula:

$$
U_{L J}(r)=4 \varepsilon\left[\left(\frac{\sigma}{r}\right)^{12}-\left(\frac{\sigma}{r}\right)^{6}\right]=\varepsilon\left[\left(\frac{r_{m}}{r}\right)^{12}-2\left(\frac{r_{m}}{r}\right)^{6}\right]
$$

where $\varepsilon$ represents the depth of Lenard-Jones potential or its minimum value and $r_{m}$ is the distance at which Lenard-Jones potential equals its minimum value which is called the minimum distance of Lenard-Jones potential while $\sigma$ is the distance at which Lenard-Jones potential equals zero.

\section{Methods}

We find a formula for the compressibility of one component fluid from the solutions of the Ornstein-Zernike equation for Lenard-Jones potential using mean spherical approximation for the direct correlation function. We obtain the radial distribution function of the system and from this function we get the compressibility of the system which is related to the radial distribution function via the following formula $[1,7,11]$ :

$$
\frac{\chi_{T}}{\chi_{T}^{i d}}=1+\rho \int g(r) d \vec{r}-\rho \int d \vec{r}
$$

where $\beta=1 /\left(k_{B} T\right), \chi_{T}^{i d}$ is the compressibility of ideal gas and $g(r)$ is the radial distribution function of the system. So, If we use the solutions of the Ornstein-Zernike equation of Lenard-Johns potential from mean spherical approximation in the previous equation and if we use the integral of the position instead of the integral of the volume in the homogeneous and isotropic case, we find that the compressibility of the system is given by the following integral equation:

$$
\chi_{T}=\chi_{T}^{i d}-C_{1} \int_{0}^{d} r^{2} d r-C_{2} \int_{d}^{\infty}\left[\alpha^{2}{\frac{d}{r^{10}}}^{12}-\alpha{\frac{d^{4}}{r^{4}}}^{6}\right] d r
$$

where $C_{1}, C_{2}$ are coefficients and $\alpha$ is defined as follows:

$$
\alpha=(1+\sqrt{1+1 / \beta \varepsilon}) / 2
$$

By integrating the equation of the compressibility over the position, we find the following formula of the compressibility:

$$
\chi_{T}=\left[1-\frac{4}{3} \pi \rho\left(1-\alpha \beta U_{0}+\frac{\alpha^{2}}{3} \beta U_{0}\right) d^{3}\right] \chi_{T}^{i d} ; \quad U_{0}=4 \varepsilon
$$

\section{Results and discussion}

The previous equation represents the basic thing of this study which is the formula of the compressibility. We see that the formula of the compressibility that we found (Eq. 7) contains the Lennard-Jones potential parameters, the diameter of particles in the system, the temperature and the density of the system's particles. We can use the formula in a wide variety of materials interacting with each other via Lennard-Jones potential such as light polymers and some simple fluids systems such as atomic Argon. In this work, we use this formula to calculate the compressibility and the bulk modulus for some hydrocarbons and air. Besides and based on the formula, we calculate the speed of sound in some atomic fluids such as Argon, some hydrocarbons, diatomic fluid such as Oxygen and some other gases such as dichlorodifluoromethane. We calculated the compressibility and the bulk modulus of air from this study, i.e. Eq. 7, at 298.16 $\mathrm{K}^{\circ}$ and we inserted the results in Table 1 with the value of bulk modulus of air found in some literatures in addition to the Lenard-Jones potential's parameters of air.

As we see from Table 1, the result resulted from this work and the result found in the literatures for the bulk modulus of air are close to each other at the previous temperature. 
In addition to that, we calculated the compressibility of air from the formula we derived in this work at different temperatures and we inserted the results of this calculation in Table 2. With the bulk modulus of air at the same temperatures. As we see from Table 2,

Table 1 The compressibility and the bulk modulus of air $B$ from Eq. 7 and the bulk modulus of air from the literatures B* at $25^{\circ} \mathrm{C}$

\begin{tabular}{lllccc}
\hline $\begin{array}{l}\sigma \\
\left(\mathrm{A}^{\circ}\right)\end{array}$ & $\varepsilon \times 10^{2}(\mathrm{ev})$ & $T\left(K^{\circ}\right)$ & $\begin{array}{c}\chi_{\mathrm{T}} \\
\left(\mathrm{MPa}^{-1}\right)\end{array}$ & $\begin{array}{c}\mathrm{B} \\
(\mathrm{MPa})\end{array}$ & $\begin{array}{c}\mathrm{B}^{*} \\
(\mathrm{MPa})\end{array}$ \\
\hline 3.6170 & 1.033 & 298.16 & 9.7929 & 0.1021 & 0.1010 \\
\hline
\end{tabular}

the bulk modulus of air increases when temperature increases which agree well with literatures.

Also, We calculated the speeds of sound in some inert gases (Helium, Neon, Argon, Krypton and Xenon) based on the formula which we found and the results were illustrated in Table 3 with the densities, the molar masses and Lenard-Jones potential parameters of the noble gases.

As we see from Table 3, the values of the speed of sound of the noble atomic gases which we calculated from this study based on the simple formula that we found have the same order with other references [26-30] for the gaseous Helium, references $[26,30]$ for the gaseous Neon, references $[26-28,30]$ for the gaseous Argon and references $[28,30]$ for the gaseous Krypton and the gaseous Xenon.

Table 2 The compressibility of air and the bulk modulus of air based on Eq. 7 at different temperatures in the gaseous phase

\begin{tabular}{|c|c|c|c|c|c|c|c|}
\hline $\begin{array}{c}t \\
\left(C^{\circ}\right)\end{array}$ & $\begin{array}{c}\rho_{m} \\
(m g / c c)\end{array}$ & $\begin{array}{c}\chi_{\mathrm{T}} \\
\left(\mathrm{MPa}^{-1}\right)\end{array}$ & $\begin{array}{l}\mathrm{B} \times 10 \\
(\mathrm{MPa})\end{array}$ & $\begin{array}{c}t \\
\left(C^{\circ}\right)\end{array}$ & $\begin{array}{c}\rho_{m} \\
(m g / c c)\end{array}$ & $\begin{array}{c}\chi_{\mathrm{T}} \\
\left(\mathrm{MPa}^{-1}\right)\end{array}$ & $\begin{array}{l}\mathrm{B} \times 10 \\
(\mathrm{MPa})\end{array}$ \\
\hline-25 & 1.4224 & 9.8726 & 1.0129 & 5 & 1.2844 & 9.7480 & 1.0259 \\
\hline-24 & 1.4178 & 9.8647 & 1.0137 & 6 & 1.2798 & 9.7478 & 1.0259 \\
\hline-23 & 1.4132 & 9.8570 & 1.0145 & 7 & 1.2752 & 9.7479 & 1.0259 \\
\hline-22 & 1.4086 & 9.8495 & 1.0153 & 8 & 1.2706 & 9.7483 & 1.0258 \\
\hline-21 & 1.4040 & 9.8424 & 1.0160 & 9 & 1.2660 & 9.7488 & 1.0258 \\
\hline-20 & 1.3994 & 9.8355 & 1.0167 & 10 & 1.2614 & 9.7497 & 1.0257 \\
\hline-19 & 1.3948 & 9.8289 & 1.0174 & 11 & 1.2568 & 9.7508 & 1.0256 \\
\hline-18 & 1.3902 & 9.8225 & 1.0181 & 12 & 1.2522 & 9.7521 & 1.0254 \\
\hline-17 & 1.3856 & 9.8164 & 1.0187 & 13 & 1.2476 & 9.7537 & 1.0252 \\
\hline-16 & 1.3810 & 9.8106 & 1.0193 & 14 & 1.2430 & 9.7556 & 1.0251 \\
\hline-15 & 1.3764 & 9.8050 & 1.0199 & 15 & 1.2384 & 9.7577 & 1.0248 \\
\hline-14 & 1.3718 & 9.7997 & 1.0204 & 16 & 1.2338 & 9.7601 & 1.0246 \\
\hline-13 & 1.3672 & 9.7947 & 1.0210 & 17 & 1.2292 & 9.7627 & 1.0243 \\
\hline-12 & 1.3626 & 9.7899 & 1.0215 & 18 & 1.2246 & 9.7656 & 1.0240 \\
\hline-11 & 1.3580 & 9.7854 & 1.0219 & 19 & 1.2200 & 9.7687 & 1.0237 \\
\hline-10 & 1.3534 & 9.7811 & 1.0224 & 20 & 1.2154 & 9.7721 & 1.0233 \\
\hline-9 & 1.3488 & 9.7771 & 1.0228 & 21 & 1.2108 & 9.7757 & 1.0229 \\
\hline-8 & 1.3442 & 9.7734 & 1.0232 & 22 & 1.2062 & 9.7796 & 1.0225 \\
\hline-7 & 1.3396 & 9.7699 & 1.0236 & 23 & 1.2016 & 9.7838 & 1.0221 \\
\hline-6 & 1.3350 & 9.7667 & 1.0239 & 24 & 1.1970 & 9.7882 & 1.0216 \\
\hline-5 & 1.3304 & 9.7637 & 1.0242 & 25 & 1.1924 & 9.7929 & 1.0211 \\
\hline-4 & 1.3258 & 9.7610 & 1.0245 & 26 & 1.1878 & 9.7978 & 1.0206 \\
\hline-3 & 1.3212 & 9.7585 & 1.0247 & 27 & 1.1832 & 9.8030 & 1.0201 \\
\hline-2 & 1.3166 & 9.7563 & 1.0250 & 28 & 1.1786 & 9.8085 & 1.0195 \\
\hline-1 & 1.3120 & 9.7544 & 1.0252 & 29 & 1.1740 & 9.8142 & 1.0189 \\
\hline 0 & 1.3074 & 9.7527 & 1.0254 & 30 & 1.1694 & 9.8202 & 1.0183 \\
\hline 1 & 1.3028 & 9.7512 & 1.0255 & 31 & 1.1648 & 9.8265 & 1.0177 \\
\hline 2 & 1.2982 & 9.7501 & 1.0256 & 32 & 1.1602 & 9.8330 & 1.0170 \\
\hline 3 & 1.2936 & 9.7491 & 1.0257 & 33 & 1.1556 & 9.8398 & 1.0163 \\
\hline 4 & 1.2890 & 9.7484 & 1.0258 & 34 & 1.1510 & 9.8468 & 1.0156 \\
\hline
\end{tabular}


Table 3 The speeds of sound in noble gases at $t=25{ }^{\circ} \mathrm{C}$ from this work based on Eq. 7

\begin{tabular}{lccccc}
\hline Substance & $\boldsymbol{H} \boldsymbol{e}$ & $\boldsymbol{N e}$ & $\boldsymbol{A r}$ & $\boldsymbol{K} \boldsymbol{r}$ & $\boldsymbol{X e}$ \\
\hline$\rho_{m}(\mathrm{mg} / \mathrm{cc})$ & 0.1786 & 0.9002 & 1.7840 & 3.7490 & 5.8940 \\
$\sigma\left(\mathrm{A}^{\circ}\right)$ & 2.576 & 2.789 & 3.432 & 3.675 & 4.009 \\
$\varepsilon / \mathrm{k}_{B}\left(\mathrm{~K}^{\circ}\right)$ & 10.2 & 35.7 & 122.4 & 170.0 & 234.7 \\
$M(\mathrm{~g} / \mathrm{mo})$ & 4.0026 & 20.1797 & 39.7920 & 83.7980 & 131.2930 \\
$V(\mathrm{~m} / \mathrm{s})$ & 787.4806 & 350.7260 & 249.5060 & 171.7220 & 136.8410 \\
\hline
\end{tabular}

Table 4 The speeds of sound in Methane, Ethylene, Propylene and Propane at $\mathbf{t}=25^{\circ} \mathrm{C}$ from this work based on Eq. 7

\begin{tabular}{lcccc}
\hline Hydrocarbon & $\mathrm{CH}_{\mathbf{4}}$ & $\boldsymbol{C}_{\mathbf{2}} \boldsymbol{H}_{\mathbf{4}}$ & $\boldsymbol{C}_{\mathbf{3}} \boldsymbol{H}_{\mathbf{6}}$ & $\boldsymbol{C}_{\mathbf{3}} \boldsymbol{H}_{\mathbf{8}}$ \\
\hline$\rho_{m}(\mathrm{mg} / \mathrm{cc})$ & 0.657 & 1.18 & 1.81 & 2.01 \\
$\sigma\left(\mathrm{A}^{\circ}\right)$ & 3.780 & 4.228 & 4.766 & 4.934 \\
$\varepsilon / \mathrm{k}_{B}\left(\mathrm{~K}^{\circ}\right)$ & 1.31 & 1.84 & 2.34 & 2.33 \\
$M(\mathrm{~g} / \mathrm{mo})$ & 16.04 & 28.05 & 42.08 & 44.10 \\
$V(\mathrm{~m} / \mathrm{s})$ & 392.6560 & 296.1230 & 240.6070 & 234.6880 \\
\hline
\end{tabular}

We see that the smallest value of the speed of sound is for Xenon and the biggest value is for Helium which also agrees with literatures.

Also, We calculated the speeds of sound in some hydrocarbons (Methane, Ethylene, Propylene and Propane) from this work, based on Eq. 7, because these hydrocarbons interact through Lenard-Jones potential like in [31], the results were inserted in Table 4 with the densities, the molar masses and Lenard-Jones potential's parameters of the used hydrocarbon materials. We used the previous hydrocarbons in the calculations of the compressibility and the bulk modulus as an example of other hydrocarbons and because the parameters of the interaction potential are known for these hydrocarbons and we can compare the bulk modules values of these hydrocarbons with other studies.

We see from Table 4 that the speed of sound agrees well with other references, references $[26-28,30]$ for the gaseous Methane and the gaseous Ethylene, reference [30] for the gaseous Propylene, references $[28,30]$ for the gaseous Propane at $25{ }^{\circ} \mathrm{C}$. In addition, we calculated the compressibility of the same hydrocarbons at temperatures equal to 0.9 of the critical temperature $T_{C}$ and pressures about 0.5 of critical pressure $P_{C}$ of each hydrocarbon from this study, i.e. Equation 7, and we inserted the results in the Table 5 which also, contains Lenard-Jones potential's parameters of these hydrocarbon materials in addition to the molar mass of the hydrocarbons. For comparison our results with other results, we calculated
Table 5 The compressibility of some hydrocarbons from Eq. 7 at 0.9 TC of each hydrocarbon

\begin{tabular}{lclcc}
\hline Hydrocarbon & $\begin{array}{c}\boldsymbol{\sigma} \\
\left(\mathbf{A}^{\circ}\right)\end{array}$ & $\begin{array}{c}\boldsymbol{\varepsilon} \times \mathbf{1 0}^{\mathbf{2}} \\
(\mathbf{e V})\end{array}$ & $\begin{array}{c}\boldsymbol{M} \\
(\boldsymbol{g} / \mathbf{m o l})\end{array}$ & $\begin{array}{c}\chi_{\boldsymbol{T}} \\
\left(\mathbf{a t m}^{\mathbf{- 1}}\right)\end{array}$ \\
\hline $\mathrm{CH}_{4}$ & 3.780 & 1.31 & 16.04 & 0.0425 \\
$\mathrm{C}_{2} \mathrm{H}_{4}$ & 4.228 & 1.84 & 28.05 & 0.0450 \\
$\mathrm{C}_{3} \mathrm{H}_{6}$ & 4.766 & 2.34 & 42.08 & 0.0794 \\
$\mathrm{C}_{3} \mathrm{H}_{8}$ & 4.934 & 2.33 & 44.10 & 0.0340 \\
\hline
\end{tabular}

Table 6 The bulk modulus of the some hydrocarbons from our work and from reference [32] at 0.9 TC of each hydrocarbon

\begin{tabular}{lccc}
\hline Hydrocarbon & $\begin{array}{c}\chi_{T} \\
\left(\text { atm }^{-1}\right)\end{array}$ & $\begin{array}{c}\mathbf{B}^{\text {ThisWork }} \\
(\text { atm })\end{array}$ & $\begin{array}{c}\mathbf{B}^{[32]} \\
(\text { atm })\end{array}$ \\
\hline $\mathrm{CH}_{4}$ & 0.0425 & 23.5294 & 29.615 \\
$\mathrm{C}_{2} \mathrm{H}_{4}$ & 0.0450 & 22.2222 & - \\
$\mathrm{C}_{3} \mathrm{H}_{6}$ & 0.0794 & 12.5945 & - \\
$\mathrm{C}_{3} \mathrm{H}_{8}$ & 0.0340 & 29.4118 & 39.487 \\
\hline
\end{tabular}

the bulk modulus at the previous temperatures for these hydrocarbons and we inserted the results with the results for the bulk modulus of these hydrocarbons at the previous conditions from reference [32] in Table 6 which also contains the compressibility from our calculations.

We calculated the speeds of sound in the same hydrocarbons at the same conditions from this study and the results were inserted in Table 7 with comparisons from reference [30] for the speeds of sound in the same hydrocarbons.

As we note from the comparisons between the values of the bulk modulus of Methane and the bulk modulus of Propane which we calculated from this study with the values of the bulk modulus of Methane and the bulk modulus of Propane resulted from reference [32] at the same conditions in Table 6, the values are of the same order and close to each other.

Also, we see the same thing from the comparisons between the values of the speed of sound in the four hydrocarbons calculated from this study and within reference [30] in Table 7 at the same conditions. After that, we calculated the values of the speed of sound in some simple diatoms gases, namely, Hydrogen, Nitrogen, Fluorine, Chlorine and Oxygen from this study, i.e. Eq. 7, and we inserted the results in Table 8. The densities, the molar masses and Lenard-Jones potential parameters of the considered diatomic simple gaseous materials were inserted in the same table. 
Table 7 The speeds of sound in the last hydrocarbons from our work and from reference [30] at the same previous conditions

\begin{tabular}{lccc}
\hline Hydrocarbon & $\begin{array}{c}\chi \boldsymbol{T} \\
\left(\boldsymbol{a t m}^{-\mathbf{1}}\right)\end{array}$ & $\begin{array}{c}\boldsymbol{v}^{\text {ThisWork }} \\
(\boldsymbol{m} / \mathbf{s})\end{array}$ & $\begin{array}{c}\boldsymbol{v}^{[\mathbf{3 0}]} \\
(\boldsymbol{m} / \boldsymbol{s})\end{array}$ \\
\hline $\mathrm{CH}_{4}$ & 0.0425 & 244.2184 & 277.62 \\
$\mathrm{C}_{2} \mathrm{H}_{4}$ & 0.0450 & 234.7020 & 257.79 \\
$\mathrm{C}_{3} \mathrm{H}_{6}$ & 0.0794 & 232.9465 & 239.00 \\
$\mathrm{C}_{3} \mathrm{H}_{8}$ & 0.0340 & 192.8914 & 194.37 \\
\hline
\end{tabular}

Table 8 The speeds of sound in Hydrogen, Nitrogen, Fluorine, Chlorine and Oxygen at $t=25{ }^{\circ} \mathrm{C}$ from this study based on Eq. 7 and from references $[26-28,30]$

\begin{tabular}{lccccc}
\hline Substance & $\boldsymbol{H}_{\mathbf{2}}$ & $\boldsymbol{N}_{\mathbf{2}}$ & $\boldsymbol{F}_{\mathbf{2}}$ & $\boldsymbol{C l}_{\mathbf{2}}$ & $\boldsymbol{O}_{\mathbf{2}}$ \\
\hline$\rho_{m}(\mathrm{mg} / \mathrm{cc})$ & 0.0823 & 1.1452 & 1.5537 & 3.2000 & 1.3087 \\
$\sigma\left(\mathrm{A}^{\circ}\right)$ & 2.915 & 3.667 & 3.653 & 4.115 & 3.433 \\
$\varepsilon / \mathrm{k}_{B}\left(\mathrm{~K}^{\circ}\right)$ & 38.0 & 99.8 & 112.0 & 357.0 & 113.0 \\
$\mathrm{M}(\mathrm{g} / \mathrm{mo})$ & 2.0159 & 28.0134 & 37.9968 & 70.9060 & 31.9988 \\
$V(\mathrm{~m} / \mathrm{s})$ & 1109.7000 & 297.4974 & 255.3772 & 185.3550 & 278.2920 \\
\hline
\end{tabular}

As we see from Table 8, the values of speed of sound in the previous diatomic simple gases which calculated from this study and the values in other studies, references $[26-28,30]$ for the gaseous Hydrogen and the gaseous Oxygen, references [26, 27, 30] for the gaseous Nitrogen, reference [30] for the gaseous Fluorine and references [26, 27] for the gaseous Chlorine, have the same order. Besides, we see that the biggest value of the speed of sound is for the Hydrogen and the smallest value is for the Chlorine. Finally, we calculated the values of the speed of sound in some gaseous oxides (Nitrous oxide, Carbon dioxide, Nitric oxide, Carbon monoxide and Sulphur dioxide) in addition to the speed of sound in dichlorodifluoromethane. We inserted the results for the previous gases in Table 9. The densities, the molar masses and Lenard-Jones potential parameters of these gaseous materials were inserted in the same table.

We see that the values of the speed of sound in the previous gases (Table 9) agree with the results from references $[26,28]$ for the gaseous Nitrous oxide and the gaseous Carbon monoxide, references $[26,28,30]$ for the gaseous Carbon dioxide and the gaseous Sulphur dioxide, reference [26] for the gaseous Nitric oxide and reference [30] for the gaseous dichlorodifluoromethane.

\section{Conclusion}

In this work, we derived analytical formula for the compressibility for homogenous and isotropic system composed of one component at low density assuming that the particles in the system interact each other via LenardJones potential which contains two parts, the first part is repulsive and the other is attractive. The compressibility can be found from some experimental methods such as [33] and some theoretical methods such as virial expansion [34, 35]. In this work, we found a formula of the compressibility as a function of particle's density, Lenard-Jones potential parameters and the temperature based on solutions of the Ornstein-Zernike equation for mean spherical approximation.

The formula we derived was employed to find the compressibility and the bulk modulus values of air at $25{ }^{\circ} \mathrm{C}$ (Tables 1 and 2) and of some hydrocarbons at defined temperatures of each hydrocarbon (Tables 5 and 6), the results of the bulk modulus and the compressibility found from this study agree qualitatively with the literature for air and other reference [32] for hydrocarbons. Besides, the speeds of sound in some hydrocarbons at defined temperatures of each hydrocarbon (Tables 4 and 7) and the speeds of sound in Helium, Neon, Argon, Krypton, Xenon, Hydrogen, Nitrogen, Oxygen, Chlorine, Fluorine, Methane, Ethylene, Propylene, Propane, Carbon monoxide, Carbon dioxide, Sulfur dioxide, Laughing gas, Nitric oxide and dichlorodifluoromethane (Tables 3, 8 and 9).

Table 9 The speeds of sound in Nitrous oxide, Carbon dioxide, Nitric oxide, Carbon monoxide, Sulphur dioxide and Dichlorodifluoromethane at $\mathrm{t}=25^{\circ} \mathrm{C}$ from this work based on Eq. 7

\begin{tabular}{|c|c|c|c|c|c|c|}
\hline Substance & $\mathrm{N}_{2} \mathrm{O}$ & $\mathrm{CO}_{2}$ & NO & $\mathrm{CO}$ & $\mathrm{SO}_{2}$ & $\mathrm{CCl}_{2} \mathrm{~F}_{2}$ \\
\hline$\rho_{m}(m g / c c)$ & 1.8088 & 1.8079 & 1.3402 & 1.1453 & 2.6642 & 2.0383 \\
\hline$\sigma\left(\mathrm{A}^{\circ}\right)$ & 3.879 & 3.996 & 3.470 & 3.590 & 4.026 & 5.116 \\
\hline$\varepsilon / k_{B}\left(K^{\circ}\right)$ & 220.0 & 190.0 & 119.0 & 110.0 & 363.0 & 280.0 \\
\hline$M(\mathrm{~g} / \mathrm{mol})$ & 44.0128 & 44.0095 & 30.0061 & 28.0101 & 64.0640 & 120.9140 \\
\hline$v(\mathrm{~m} / \mathrm{s})$ & 236.6072 & 236.7511 & 287.3415 & 297.4551 & 195.2006 & 142.5648 \\
\hline
\end{tabular}




\section{We found that our results agree qualitatively with other studies.}

The formula that we derived for the compressibility (Eq. 7) is simple and it can be applied for many fluids that interact via Lenard-Jones potential, only, we need the Lenard-Jones potential parameters and the density of particles in the system at a certain temperature.

\section{Abbreviations}

OZE: Ornstein-Zernike Equation; MSA: Mean Spherical Approximation; BGYA : Born Green Yvon Approximation; HNCA: Hyper Netted Chain Approximation; RDF: Radial Distribution Function; PYA: Percus Yevick Approximation.

\section{Acknowledgments \\ Not applicable.}

\section{Authors' contributions}

MAR contributed to the derivation of the method and calculations of the results and discussion. MSED contributed to the writing of conclusions and references. All authors read and aproved the final manuscript.

\section{Funding}

Not applicable.

\section{Availability of data and materials}

We declared that the materials in the paper will be available for non-commercial purposes and the corresponding author, M Al-Raeei, must be contacted for requesting the data.

\section{Competing interests}

The authors confirmed that they do not have a conflict of interest.

\begin{abstract}
Author details
${ }^{1}$ Faculty of Sciences, Damascus University, Damascus, Syrian Arab Republic. 2 Faculty of Informatics and Communications, Arab International University, Daraa, Syrian Arab Republic. ${ }^{3}$ Higher Institute of Laser Applications and Researches, Damascus University, Damascus, Syrian Arab Republic.
\end{abstract}

Received: 6 May 2020 Accepted: 31 July 2020

Published online: 09 August 2020

\section{References}

1. Osiele OM (2006) Calculation of the structure factor of liquid metals. Niger J Phys 25:32. https://doi.org/10.4314/njphy.v18i1.38078

2. Bandyopadhyay P, Gupta-Bhaya P (2019) A comparative evaluation of pair correlation functions for a highly asymmetric electrolyte with mono and divalent counterions from integral equation theory in hypernetted chain (HNC) approximation and Monte Carlo simulation. Chem Phys Lett 732:136664. https://doi.org/10.1016/j.cplett.2019.136664

3. Al-Raeei M, El-Daher MS (2020) Temperature dependence of the specific volume of Lennard-Jones potential and applying in case of polymers and other materials. Polym Bull. https://doi.org/10.1007/s00289-020-03166-08

4. Nägele G (2004) The physics of colloidal soft matter. Centre of Excellence for Advanced Materials and Structures, Warsaw

5. Al-Raeei M, El-Daher MS (2018) Analytical static structure factor for a two-component system interacting via van der Waals potential. Pramana J Phys 90:60. https://doi.org/10.1007/s12043-018-1550-0

6. Waisman E et al (1973) Ornstein-Zernike equation for a two-Yukawa c(r). Chem Phys Lett 40:514-516. https://doi.org/10.1016/0009-2614(76)85132-9

7. Al-Raeei M (2018) Using methods of statistical mechanics in the study of soft condensed matter materials and complex structures. Damascus University Publishing Syrian Arab Republic, Damascus, Master thesis

8. Zarezadeh Z, Costantini G (2019) Lorentz excitable lattice gas automata (LELGA) for optimization of Lennard-Jones atomic cluster size up to
$N \leq$ 383. Chem Phys Lett 727:45-49. https://doi.org/10.1016/j.cplet t.2019.04.046

9. Al-Raeei M, El-Daher MS (2019) A numerical method for fractional Schrödinger equation of Lennard-Jones potential. Phys Lett A 383:125831. https://doi.org/10.1016/j.physleta.2019.07.019

10. Demirel $Y$ (2014) Nonequilibrium thermodynamics: transport and rate processes in physical, chimical and biological systems. Elsevier, Amsterdam

11. Vargas P et al (2001) Second virial coffcient for the Lennard-Jones potential. Phys A 290:92-100. https://doi.org/10.1016/S0378-4371(00)00362-9

12. Yadav CP, Pandey DK (2019) Pressure- and orientation-dependent elastic and ultrasonic characterisation of quartzite boron nitride. Pramana J Phys 92:5. https://doi.org/10.1007/s12043-018-1666-2

13. Handrey C, Ferraz F (2019) Influence of the long-range forces in nonGaussian random-packing dynamics. Phys Lett A 38:125884. https://doi. org/10.1016/j.physleta.2019.125884

14. Wang Y, Wang C, Tan H (2019) Intrinsic edge warping of graphene nanoribbon boost molecular directional motion: toward the novel nanodevices. Phys Lett A 383:1473-1477. https://doi.org/10.1016/j.physl eta.2019.01.054

15. Goujon F, Ghoufi A, Malfreyt P (2018) Size-effects on the surface tension near the critical point: Monte Carlo simulations of the Lennard-Jones fluid. Chem Phys Lett 694:60-64. https://doi.org/10.1016/j.cplet t.2018.01.046

16. Zhou S, Solana JR (2017) Thermodynamic properties of fluids with Lennard-Jones-Gauss potential from computer simulation and the coupling parameter series expansion. Mol Phys 116:491. https://doi. org/10.1080/00268976.2017.1406162

17. Al-Raeei M, El-Daher MS (2019) Analytical formula of heat capacity in soft matter materials using Lennard-Jones potential. Chem Phys Lett 734:136729. https://doi.org/10.1016/j.cplett.2019.136729

18. Miyata T, Tange K (2018) Performance of Kobryn-Gusarov-Kovalenko closure from a thermodynamic viewpoint for one-component LennardJones fluids. Chem Phys Lett 700:88-95. https://doi.org/10.1016/j.cplet t.2018.04.013

19. Al-Raeei M, El-Daher MS (2020) An algorithm for fractional Schrödinger equation in case of Morse potential. AIP Adv 10:035305. https://doi. org/10.1063/1.5113593

20. Al-Raeei M, El-Daher MS (2019) On: new optical soliton solutions for nonlinear complex fractional Schrödinger equation via new auxiliary equation method and novel ( $\left.\mathrm{G}^{\prime} / \mathrm{G}\right)$-expansion method. Pramana J Phys 94:9. https://doi.org/10.1007/s12043-019-1877-1

21. Ushcats $\mathrm{S}$ et al (2018) Asymptotics of activity series at the divergence point. Pramana J Phys 91:31. https://doi.org/10.1007/s12043-018-1604-3

22. Jones JE (1924) On the determination of molecular fields. II. From the equation of state of a gas. Proc R Soc Lond A 106:463-477. https://doi. org/10.1098/rspa.1924.0082

23. Tarabichi S et al (2016) Physics for the prearatory year of medical colleges. Ministry of Higher Education Publishing, Syrian Arab Republic

24. Al-Raeei M, El-Daher MS (2020) Numerical simulation of the space dependent fractional Schrödinger equation for London dispersion potential type. Heliyon 6:e04495. https://doi.org/10.1016/j.heliyon.2020. e04495

25. Al-Raeei M (2020) The forecasting of COVID-19 with mortality using SIRD epidemic model for the United States, Russia, China, and the Syrian Arab Republic. AIP Adv 10:065325. https://doi.org/10.1063/5.0014275

26. Lide DR (2003) CRC handbook of chemistry and physics. CRC Press, Boca Raton

27. Samsonov G (1968) Handbook of the physicochemical properties of the elements. IFI-Plenum, New York

28. Zuckerwar AJ (2002) Handbook of the speed of sound in real gases. Academic Press, San Diego

29. Gand SW et al (2011) The velocity of sound in helium at temperatures $-78{ }^{\circ} \mathrm{C}$ to $200{ }^{\circ} \mathrm{C}$ and pressures up to 70 atmospheres. Can J Res 28a(5):509-519

30. National Institute of Standard and Technology. https://www.nist.gov/. Accessed 10 May 2020

31. Olanipekun AB (2017) Shear properties of liquid methane. Int J Math Phys Sci Res 5:129-135 
32. Ghazi PK (2013) Discrimination of fizz water and gas reservoir by AVO analysis: a modified approach. Acta Geod Geophys 48:347-361. https:// doi.org/10.1007/s40328-013-0023-7

33. Mot PH et al (2008) The bulk modulus and Poisson's ratio of "incompressible" materials. J Sound Vib 312:572-575

34. Bavaud F et al (1986) Statistical mechanics of elastic moduli. J Stat Phys 42:621-646
35. Vargas P et al (2001) Second virial coffcient for the Lennard-Jones potential. Phys A 290:92-100

\section{Publisher's Note}

Springer Nature remains neutral with regard to jurisdictional claims in published maps and institutional affiliations.
Ready to submit your research? Choose BMC and benefit from:

- fast, convenient online submission

- thorough peer review by experienced researchers in your field

- rapid publication on acceptance

- support for research data, including large and complex data types

- gold Open Access which fosters wider collaboration and increased citations

- maximum visibility for your research: over 100M website views per year

At BMC, research is always in progress.

Learn more biomedcentral.com/submissions 